\title{
A GUERRA AO TERROR E A PRIVATIZAÇÃO DA FORÇA: uma primeira análise do uso de companhias militares privadas nas intervenções estadunidenses no pós-onze de setembro
}

\author{
Priscila Borba da Costa*
}

\section{Resumo}

O presente artigo realiza uma breve análise histórica sobre as companhias militares privadas e sua progressiva presença nas intervenções militares promovidas pelos Estados Unidos desde o fim da Guerra Fria. A partir de um recorte específico, o período da “Guerra ao Terror” promovida pelo governo Bush, o presente estudo propõe uma análise preliminar sobre as principais companhias militares em atuação hoje, os limites regulatórios das companhias militares privadas, os interesses por trás da crescente utilização deste tipo de serviço e os desafios para compreensão deste fenômeno na formatação dos assuntos militares no século XXI.

Palavras-chave: Companhias militares privadas. Guerra ao Terror. Política externa. Estados Unidos da América.

\section{Introdução: da Guerra Fria à intensificação da privatização das forças militares no século $\mathrm{XXI}^{1}$}

A guerra será vencida em grande parte por forças que você desconhece, com ações que você não vai ver e mediante expedientes sobre os quais você vai preferir não saber nada. Mas nós vamos vencer (A.B. "Buzzy" Kongrad - exdiretor executivo da CIA - outubro de 2001) ${ }^{2}$

\footnotetext{
* Mestranda em História pela Universidade Estadual de Maringá. E-mail: pri.historia@hotmail.com

${ }^{1}$ Este artigo é resultado de um primeiro mapeamento do tema das companhias privadas de segurança dos Estados Unidos. Um trabalho mais aprofundado será desenvolvido e apresentado nos próximos dois anos, período referente ao Mestrado cursado na Universidade Estadual de Maringá, no Paraná. O objetivo do artigo é compartilhar os estudos com a comunidade científica envolvida com a História do Tempo Presente, assim como com as demais áreas que contribuem ao tema, para que o desenvolvimento desses estudos, unido às críticas e sugestões, contribua da forma mais satisfatória possível ao fim do período mencionado.

2 SCAHILL, J. Blackwater: a ascensão do exército mercenário mais poderoso do mundo. São Paulo: Companhia das Letras, 2008, nota $n^{\circ}$ 95, p. 114.
} 
Se o extremo século XX foi “a era mais extraordinária da história da humanidade, combinando catástrofes humanas de dimensões inéditas, conquistas materiais substanciais e um aumento sem precedentes da nossa capacidade de transformar e talvez destruir o planeta” (HOBSBAWM, 2007, p. 9), os fatos sociais e políticos do recém-iniciado século XXI lançam novos desafios para o papel do historiador de examinar, analisar e compreender a situação do mundo no início do terceiro milênio. Vive-se um tempo de constantes crises econômicas resultante da instabilidade da globalização do capitalismo financeiro e de seus frágeis marcos regulatórios, de convulsões sociais em países de antigos regimes ditatoriais implantados no processo de descolonização que sucedeu o pós-II Guerra e de ações, grosso modo, denominadas como terroristas que se voltam às práticas opressoras, colonizadoras e neocolonizadoras das tradicionais potências ocidentais, tal como o amplamente televisionado ataque às torres do World Trade Center em Nova Iorque no dia 11 de Setembro de 2001, evento que impulsionou a Guerra ao Terror e deu início a um novo momento de tensões após a autoanunciada vitória dos Estados Unidos da América sobre a União Soviética na Guerra Fria $^{3}$ e a falsa imagem de "fim da história” do capitalismo democrático baseado no consumo, tal como proclamado pelo historiador estadunidense Francis Fukuyama ${ }^{4}$

Apesar do esforço de líderes políticos de ricas nações industriais do século passado de criar instituições internacionais com missões pacifistas, como a Organização das Nações Unidas, a hipotética harmonia global está longe de ser atingida. A pretensiosa pax americana não foi alcançada. O momento de euforia do final da Guerra Fria criou uma falsa ilusão de harmonia: o mundo tornou-se diferente no início da década de 1990, mas não necessariamente mais pacífico. O fim da Guerra Fria encerrou a ameaça de uma guerra global e nuclear entre superpotências, mas não foi capaz de evitar uma série de conflitos étnicos e políticos em países do Leste Europeu, Ásia e África e a ascensão de grupos organizados no Oriente Médio de orientação “antiocidental”, em razão dos imperialistas jogos estratégicos para opressão e utilização de recursos naturais da região para fins econômicos ${ }^{5}$.

A tarefa de líder de uma nova ordem internacional hegemônica, democrática e liberal, tornou-se problemática para os Estados Unidos, que intensificou seu papel de interventor militar sob a justificativa da “segurança global” e dos “direitos humanos”. As pretensões

\footnotetext{
3 Para uma análise esclarecedora da Guerra Fria, cf. Sidnei José Munhoz. 'Guerra Fria: um debate interpretativo’, TEIXEIRA DA SILVA, F.C. (coord.). O Século Sombrio: Uma História Geral do Século XX. Rio de Janeiro: Editora Campus Elsevier, 2004, p. 261-281.

${ }^{4}$ Cf. FUKUYAMA, F. O Fim da História e o Último Homem. Rio de Janeiro: Rocco, 1992.

${ }^{5}$ Como relata Noam Chomsky, Osama Bin Laden, líder islâmico da organização Al-Qaeda, proclamava que a violência era justificada como legítima defesa contra os infiéis que invadiram e ocuparam terras Islãs e contra os governos brutais e corruptos que os infiéis (os estadunidenses) sustentavam ali. Cf. CHOMSKY, N. Pirates and Emperors, Old and New: international terrorism in the real world. Cambridge: South End Press, 2002.
} 
universalistas dos Estados Unidos (ícone maior do Ocidente capitalista) levaram o país cada vez mais para o conflito com outras civilizações, de forma mais grave com o Islã ${ }^{6}$. Em reação às violências cometidas pelo "império americano"7 no Oriente, atentados terroristas planejados por grupos radicais passaram a ocorrer com mais frequência e novas intervenções militares foram realizadas sob o pretexto de combater o "eixo do mal” e o terrorismo, em especial no Iraque e no Afeganistão. A esse cenário de instabilidade e conflito em tempos de globalização, soma-se um fenômeno peculiar que chama a atenção dos cientistas sociais: a crescente privatização das forças armadas nas intervenções militares no pós-Guerra Fria, algo que rompe com a ideia de monopólio do uso legítimo da força pelo Estado.

O presente artigo propõe uma análise preliminar sobre o fenômeno da utilização das companhias militares privadas nas intervenções militares do século XXI. Para tanto, o estudo apresenta uma breve história da presença dos mercenários nos conflitos bélicos dos últimos séculos, como eles diferem da estrutura atual das companhias militares privadas, a utilização das companhias em confrontos na África e no Oriente Médio no século XX e a intensificação da contratação de tais companhias na “Guerra ao Terror” promovida pelo governo Bush após os atentados de 11 de setembro, evento que simboliza o início de uma nova fase militar e uma redefinição da política dos Estados Unidos para assuntos militares.

Com base em pesquisa bibliográfica, leitura de reportagens investigativas e análise de documentos oficiais publicados pelo Departamento de Estado dos Estados Unidos e pelo parlamento do Reino Unido, o presente artigo não trata do tema de forma completa, mas apresenta dados importantes para compreensão das companhias militares privadas e propõe uma agenda de pesquisa para historiadores envolvidos com o estudo do tempo presente no que diz respeito a assuntos militares e novas formas bélicas.

\footnotetext{
${ }^{6}$ Ainda que o termo “civilizações” seja utilizado, a palavra Islã não se refere a todos os países do Oriente Médio de orientação islâmica, mas sim à religião no sentido amplo, considerando o embate religioso promovido pelos Estados Unidos da América.

${ }^{7}$ Historicamente, a política externa imperial dos Estados Unidos tem origem no esgotamento da fase de expansão interna das suas fronteiras no final do século XIX. Como explica Sidnei Munhoz, "os EUA buscaram superar a crise doméstica ocasionada pelo desenvolvimento de uma capacidade de produção muito superior à demanda interna, mediante o emprego de políticas expansionistas. Assim, adotaram uma política externa imperial com o objetivo de solucionar a crise do seu mercado doméstico, o que os teria levado à guerra com a Espanha, e, em consequência, propiciou a independência formal de Cuba, a anexação de Porto Rico e o domínio sobre as Filipinas e Guam. Desse modo, a guerra, inicialmente justificada como uma luta para apoiar a independência de um povo oprimido, acabou fazendo com que os EUA se tornassem uma potência imperial”. MUNHOZ, S. J. Algumas Reflexões Sobre a Política Externa Norte-Americana Durante o Século XX, in: Darc Costa e TEIXEIRA DA SILVA, F.C. (org.), Mundo Latino e Mundialização. Rio de Janeiro: Mauad, 2004, p. 240.
} 


\section{O retorno dos mercenários: o fenômeno das "companhias militares privadas"}

Apesar de ser um tema pouco discutido no Brasil, alguns pesquisadores filiados a universidades, ONGs e instituições internacionais têm investigado a origem e evolução das Private Military Companies (PMCs). A agenda, entretanto, é recente e carece de um corpo teórico sólido. Há dez anos, na revista International Security, o cientista político Peter W. Singer alertava para a ausência de estudos abrangentes sobre a indústria das companhias militares privadas (CMP):

Infelizmente, nossa compreensão deste mercado é limitada teoricamente, conceitualmente e até mesmo geograficamente. Muito do que tem sido escrito sobre companhias militares privadas foca em estudos de caso sobre empresas específicas e é confinado a determinadas regiões, geralmente na África, e não na indústria em geral. Além do mais, não há base ou arcabouço teórico de análise para elucidar a variação das atividades das companhias privadas ou seu impacto, não há tentativa de examinar a indústria na perspectiva econômica tampouco política, não há análise comparativa das CMP com empresas em outras indústrias ou entre a indústria em si, e não há exploração do que a presença dessas empresas significa para os estudos de segurança (SINGER, 2001, p. 189) ${ }^{8}$.

Para Singer, as companhias militares privadas são distintas dos mercenários, guerreiros que lutam apenas por ganho monetário pessoal, velhos personagens da história da humanidade desde a Grécia Antiga ${ }^{9}$. Em sua obra Corporate Warriors (2008), Singer demonstra que o monopólio da força pelo Estado foi exceção e não a regra na história da humanidade. De fato, desde o século XIII há registros de companhias (con pane, grupos organizados que recebiam o pagamento em pão para serviços militares) que ofereceram seus serviços para quem pudesse pagar melhor. Há relatos de companhias em grande parte da história bélica do ocidente europeu dos séculos XV e XVI, marcada pela contratação de soldados privados estrangeiros (companhias e mercenários) e pela completa barbárie. Apenas com o Tratado de Westfália (1648), assinado após o fim da Guerra dos Trinta Anos, é que líderes do Ocidente afirmam o princípio da soberania estatal para assuntos internos, contexto no qual "exércitos de estrangeiros contratados começam a ser substituídos por exércitos estatais formados por súditos” (SINGER, 2008, p. 29) ${ }^{10}$.

\footnotetext{
${ }^{8}$ Tradução livre.

${ }^{9}$ Cf. LANNING, M.L. Mercenaries: soldiers of fortune from ancient Greece to today's private military companies. New York: Ballantine, 2005.

${ }^{10}$ Tradução livre.
} 
O ponto de inflexão desta mudança foram as guerras napoleônicas do final do século XVIII, período que as guerras dos reis tornaram-se as guerras dos povos. Com a criação do conceito de Estado-nação, imperadores, monarcas absolutos e monarcas constitucionais buscavam expandir suas burocracias, seus exércitos, sua força econômica mercantilista e o território sobre o qual reinavam. Como relata o cientista político Samuel Huntington, “a partir da Revolução Francesa, as principais linhas de conflito passaram a ocorrer entre nações em vez de entre príncipes” (HUNTINGTON, 2007, p. 60).

Perter Singer explica que a prática da guerra foi modificada como resposta à mudança de mentalidade gerada pelo Iluminismo com relação à identidade do Estado-nação. Ideias sobre o contrato social e o racionalismo forneceram uma nova forma de pensar sobre a relação entre Estado e soldados e cidadania e serviço. Ao contrário dos séculos anteriores, quando arranjos feudais e companhias militares prevaleciam, as pessoas estavam mais dispostas a lutar como cidadãs do que como sujeitos. Aqueles que lutavam por lucro, ao invés de patriotismo, eram completamente deslegitimados sob essas novas concepções (SINGER, 2008, p. 31). As companhias militares privadas tornam-se estranhas ao processo de racionalização e formação do Estado moderno, que, para Max Weber, é "uma associação de dominação institucional, que dentro de determinado território, pretendeu com êxito monopolizar a coação física legítima como meio da dominação e reuniu para este fim, nas mãos de seus dirigentes, os meios materiais de organização” (WEBER, 2005, p. 529). Neste formato político, o moderno exército de massas é basicamente um exército burocrático (organizado por normas jurídicas gerais e impessoais) e o oficial representa uma categoria especial de funcionário, em oposição ao cavaleiro, condottiere, cacique ou herói homérico. No século XX, o formato moderno de Estado-nação e o conceito de soberania espalham-se sobre o globo. Com eles, normas contra a utilização de soldados privados começam a ganhar força. Paralelo a esse fenômeno, o ator principal do mercado privado militar torna-se o exsoldado individual, “o que agora é concebido como mercenário” (SINGER, 2008, p. 37). O auge dos mercenários ocorreu durante o período de descolonização nas décadas de 1950 e 1960. Eles foram mais notáveis durante a Guerra do Congo de 1960 a 1964, onde unidades privadas contratadas por empresas mineradoras lutaram em apoio à secessão de Katanga. Esses grupos eram conhecidos pelo nome "Les Affreux" (Os Terríveis) e incluíam personagens notórios como o irlandês "Mad” Mike Hoare e o francês Bob Denard (SINGER, 2008, p. 38).

Apesar da coexistência de mercenários e companhias militares privadas na história da humanidade, os dois não se confundem. O que difere as companhias militares privadas dos 
mercenários (indivíduos com organização ad hoc, motivados pelo ganho, subservientes a um só cliente) é o grau de organização que define sua coesão e disciplina e a forma como esta organização disponibiliza seus serviços num mercado aberto e competitivo:

\begin{abstract}
Hoje, as companhias militares privadas representam a evolução dos atores privados no estado de guerra. O fator crítico analítico é a sua forma corporativa negocial moderna. As CMPs são hierarquicamente organizadas em negócios incorporados e registrados que trocam e competem abertamente no mercado internacional, ligadas a holdings internacionais, recrutam de forma mais proficiente que seus predecessores, e fornecem uma ampla gama de serviços militares para uma grande variedade e número de clientes. A corporatização não apenas distingue as CMPs de mercenários e outras formas de militarização privada do passado, como também oferece certas vantagens em termos de eficiência e eficácia (SINGER, 2001, p. 191).
\end{abstract}

De fato, o reaparecimento das companhias militares privadas em escala internacional após o seu descrédito no modelo de Estado-nação dos séculos XIX e XX - foi intensificado após a derrocada do socialismo real e o processo de globalização econômica. A característica que define o recente formato das companhias militares do pós-Guerra Fria é a “corporatização” dos serviços militares. Após anos de estudos, Singer entende que as companhias militares privadas (que ele chama de private military firms) são estruturadas como empresas e operam primariamente como negócios. Como entidades de negócio, tais companhias são geralmente conectadas por meio de complexas redes financeiras que a amarram a outras firmas, ambas dentro e fora desta indústria. De fato, muitas das mais ativas companhias militares privadas, como a Armorgroup ou Vinnell, são abertamente parte de corporações multinacionais.

A chegada ao poder de George W. Bush, do Partido Republicano, à presidência dos Estados Unidos da América em 20 de janeiro de 2001 é um aspecto fundamental para a análise da utilização das companhias militares privadas em intervenções militares. O projeto neoliberal de terceirização e privatização dos conflitos bélicos ganhou força com a nova equipe do governo Bush, formada por conservadores de orientação política vinculada à “direita”, ligados a grandes empresas da indústria bélica. Após os atentados de 11 de setembro, o processo foi rapidamente intensificado sob justificativa da “Guerra ao Terror”. A análise do jornalista Jeremy Scahill sintetiza a nova roupagem ideológica da composição do poder executivo federal dos Estados Unidos:

Desde o momento em que a equipe de Bush tomou o poder, o Pentágono abarrotou-se de ideólogos com Paul Wolfowitz, Douglas Feith, Zalmay 
Khalilzad e Stephen Cambone, bem como de ex-executivos de grandes empresas - muitas delas grandes fabricantes de armamentos -, como o subsecretário de Defesa Pete Aldrigde (Aerospace Corporation), o ministro do Exército Thomas White (Enron), o ministro da Marinha Gordon England (General Dynamic) e o ministro da Aeronáutica James Roche (Northrop Grumman). A nova liderança civil do Pentágono chegou ao poder com dois objetivos principais: a mudança de regime em nações estratégicas e a implementação da operação de privatização e terceirização mais abrangente da história militar dos Estados Unidos - uma revolução nos assuntos militares. Depois do 11 de setembro, essa campanha não pôde mais ser detida. (...) Mesmo enquanto o país aparentava publicamente envidar esforços diplomáticos, a [companhia militar privada] Halliburton se preparava, a portas fechadas, para a maior operação de sua história. Quando os tanques norte-americanos entraram em Bagdá, em março de 2003, transportavam com eles o maior exército de prestadores de serviços já empregado numa guerra (SCAHILL, 2008, p. 63).

Após a invasão do Afeganistão, sob justificativa da necessidade de combate à rede terrorista Al Qaeda e da caçada a Osama Bin Laden (noticiado pelo governo Obama como morto em maio de 2011), companhias militares privadas, como a até então desconhecida Blackwater $^{11}$, começaram a chamar a atenção da mídia e de estudiosos. Em razão da exposição pela cobertura jornalística, a legitimidade das companhias militares privadas tornou-se objeto de discussão em grande parte do mundo ocidental.

Carlos Ortiz, pesquisador do Centre for Global Political Economy da Universidade de Sussex, destaca que o clímax do debate sobre as companhias privadas foi atingido no Reino Unido com o lançamento do Green Paper (documento de consulta produzido pelo Parlamento para discussão de novos projetos de lei ${ }^{12}$ ) Private Military Companies: Options for Regulation, divulgado em fevereiro de 2002. Neste estudo, exigido pelo Comitê de Assuntos Externos da Câmara dos Comuns (House of Commons) como subsídio para uma nova

\footnotetext{
11 "Em menos de uma década, a Blackwater saiu de um pântano na Carolina do Norte para se tornar uma espécie de Guarda Pretoriana da 'guerra global ao terror' movida pela administração Bush. Hoje, ela tem mais de 2,3 mil soldados particulares operando em nove países, inclusive dentro dos Estados Unidos. Mantém um banco de dados com 21 mil ex-agentes e soldados das Forças Especiais, além de policiais aposentados, que pode convocar a qualquer momento. A companhia tem também uma frota particular de mais de vinte aeronaves, incluindo-se aí helicópteros de combate e uma divisão de zepelins de reconhecimento. Seu quartel-general de 28 quilômetros quadrados em Moycock, na Carolina do Norte, é a maior instalação militar privada do mundo, treinando por ano dezenas de milhares de agentes da lei, locais ou federais, bem como soldados de países estrangeiros 'amigos'. A Blackwater tem sua própria divisão de inteligência e conta, entre seus executivos, com ex-oficiais de inteligência e ex-militares graduados. Recentemente, iniciou-se a construção de novas instalações na Califórnia ('Blackwater West' e em Illinois ('Blackwater North'), assim como de um campo de treinamento na selva filipina. A companhia possui mais de 500 milhões de dólares em contratos com o governo - e isso não inclui seu orçamento secreto de operações 'clandestinas' para agências de inteligência dos Estados Unidos ou para empresas, indivíduos e governos estrangeiros. Como observou um congressista norte-americano, em termos estritamente militares, a Blackwater poderia depor muitos governos do mundo. É, portanto, um Exército particular, controlado por uma única pessoa: Erik Prince, um megamilionário cristão de extrema direita que tem sido um dos maiores financiadores não apenas das campanhas do presidente Bush, como também da direita cristã em geral”. SCAHILL, J. Blackwater. São Paulo: Companhia das Letras, 2008, p. 65.

${ }^{12}$ Disponível em: <http://www.parliament.uk/site-information/glossary/green-papers/> .
} 
proposta regulatória, destaca-se o fato de que Estados e organizações internacionais estão se voltando para o setor privado como uma forma eficiente em termos de custos de procurar serviços, os quais foram anteriormente de preservação exclusiva militar. Com base em dados da ONG International Alert de 1999, o estudo discutido no parlamento britânico aponta que atividades de companhias militares privadas ocorreram em Caxemira, Afeganistão, Libéria, República Democrática do Congo, Angola, República do Congo, Serra Leoa, antiga Iugoslávia, Etiópia e Eritreia (fronteira com Sudão), dentre outros. Baseado numa pesquisa prévia de Kevin O’Brien e David Shearer, o Green Paper apresenta uma tabela de exemplos de atividades de companhias militares privadas:

\begin{tabular}{|l|l|l|}
\hline \multicolumn{2}{|l|}{ Tabela 1: Atividades, exemplos e usuários de companhias militares privadas e de segurança } \\
\hline Atividades e serviços fornecidos & Exemplos de companhias & Principais usuários dos serviços \\
\hline Apoio a combate e operacional & $\begin{array}{l}\text { Executive Outcomes, Sandline } \\
\text { International, Gurkha Security } \\
\text { Guards }\end{array}$ & Governos \\
\hline Conselho militar e treinamento & $\begin{array}{l}\text { DSL, MPRI, Silver Shadow, } \\
\text { Levdan, Vinnel, BDM }\end{array}$ & Governos \\
\hline Obtenção de armas & $\begin{array}{l}\text { Executive Outcomes, Sandline } \\
\text { International, Levdan }\end{array}$ & Governos \\
\hline Serviço de inteligência & $\begin{array}{l}\text { Control Risk Group, Kroll, Saladin, } \\
\text { DynCorp }\end{array}$ & $\begin{array}{l}\text { Governos, Companhias } \\
\text { Multinacionais }\end{array}$ \\
\hline $\begin{array}{l}\text { Serviços de prevenção de } \\
\text { segurança e crime }\end{array}$ & $\begin{array}{l}\text { DSL, Lifeguard, Group 4, Control } \\
\text { Risk Group, Gurkha, Security } \\
\text { Guards, Gray Security, Coin } \\
\text { Security }\end{array}$ & $\begin{array}{l}\text { Companhias Multinacionais, } \\
\text { Agências Humanitárias }\end{array}$ \\
\hline Apoio logístico & Archtects and Engineers (PAE) & $\begin{array}{l}\text { Organizações Mantenedoras da } \\
\text { Paz, Agências Humanitárias }\end{array}$ \\
\hline
\end{tabular}

Fonte: Comitê de Assuntos Externos, Câmara dos Comuns, Reino Unido, 2002.

Grande parte das companhias militares privadas está sediada nos Estados Unidos e presta serviço ao governo estadunidense. Como aponta Márcio Scalercio, mestre em História Social e doutor em Relações Internacionais (PUC-RJ), entre 1992 e 2002, as CMPs sediadas nos Estados Unidos assinaram mais de 3000 contratos no valor estimado de U\$ 300 bilhões com o Departamento de Defesa daquele país. O faturamento projetado para o ano de 2010 foi de U\$ 202 bilhões. Jeremy Scahill traz os números do verão de 2007, quando, segundo ele, havia mais "servidores particulares” - cerca de 180 mil (630 empresas que contratavam mais de cem países de todo o mundo) - trabalhando para os Estados Unidos no Iraque, do que soldados regulares do Exército, que contabilizavam cerca de 160 mil, ou seja, “o próprio 
Exército tornou-se um parceiro minoritário na coalizão que ocupa o Iraque” (SCAHILL, 2008, p.56).

No tocante aos serviços prestados por essas companhias militares privadas, é possível listar, dentre outros, os seguintes: (i) treinamento militar, (ii) treinamento policial, (iii) comando e controle, (iv) logística e transporte, (v) planejamento de operações, (vi) inteligência, (vii) guarda-costas, (viii) operação de equipamentos sofisticados, (ix) prevenção de crime, (x) contra-insurgência, (xi) antiterrorismo, (xii) telecomunicações, (xiii) refeições, (xiv) lavanderia, (xv) serviços administrativos. Uma lista atualizada em 2010 com todas as companhias militares privadas em atuação (e a descrição de suas atividades) foi publicada pelo portal Private Military e está disponível para consulta pública na internet ${ }^{13}$.

As intervenções militares estadunidenses no pós-11 de setembro, em especial no Afeganistão e Iraque, caracterizam-se pela crescente demanda por serviços oferecidos por tais companhias privadas, que possuem um corpo de soldados especialmente treinados para manejo de armas e equipamento de alta tecnologia em regiões inóspitas. Tais companhias são comandas por antigos militares que integraram a burocracia militar estadunidense durante a Guerra Fria. O governo estadunidense justifica-se perante a sociedade alegando que tais empresas garantem um serviço militar melhor e mais eficiente, evitando um maior número de mortes em conflitos. O grande problema, entretanto, é a ausência de normas internacionais que determinem os limites de atuação das companhias militares privadas e penalizações aplicáveis para “contratados” que possam praticar crimes como homicídio, abuso sexual, lesão corporal, tortura e outros atos de violência considerados ilícitos na esfera internacional.

\section{Impasses legais da privatização da força militar}

Diante desta revolucionária forma de “fazer guerra”, há uma dificuldade quanto à delimitação clara nos limites de atuação destas companhias privadas, algo que entrou em discussão pública na mídia após escândalos envolvendo as empresas de segurança estadunidenses. Como exemplo, é possível citar os casos de tortura ocorridos na penitenciária de Abu Ghraib ${ }^{14}$ (após a invasão do Iraque, muitos dos prisioneiros foram torturados e executados por soldados que haviam recebido treinamento destas companhias militares

\footnotetext{
${ }^{13}$ Cf. Disponível em: <http://www.privatemilitary.org/private_military_companies.html>.

${ }^{14}$ Para uma amostra da crueldade utilizada pelos soldados estadunidenses, cf. HERSH, S. Cadeia de comando. Rio de Janeiro: Ediouro, 2004. O leitor pode conferir também as fotos da prisão de Abu Ghraib, publicadas pelo Washington Post: <http://www.washingtonpost.com/wp-srv/flash/photo/world/2004-0503_prisonabuse/index_frames.htm?startat=1\&indexFile=world_2004-05-03_prisonabuse>.
} 
privadas) e os escândalos envolvendo a companhia Blackwater após o massacre da Praça Nisour, em Bagdá, no Iraque, quando o comboio da empresa disparou propositalmente contra os civis que estavam no cruzamento da Praça, alegando terem sido ameaçados por tiros. A empresa alvejou dezenas de civis, tirando a vida de 17 iraquianos inocentes ${ }^{15}$. A Blackwater ficou mundialmente conhecida após esse massacre, numa época em que a mídia internacional pouco noticiava sobre a existência de tal modalidade de força militar.

Em 27 de junho de 2004, o embaixador Paul Bremer, à época na Autoridade Provisória da Coalizão, emitiu um decreto conhecido como Ordem 17 que "garantia ampla imunidade a servidores privados trabalhando para os Estados Unidos no Iraque, barrando o governo do Iraque de processar servidores estadunidenses em cortes domésticas pelos crimes cometidos” (SCAHILL, 2008, p.24). Scahill revela que até a publicação de seu livro “Blackwater: a ascensão do exército mercenário mais poderoso do mundo”, nenhum prestador de serviços militares contratados no Iraque, fosse da companhia foco de sua pesquisa ou qualquer outra, havia sido acusado criminalmente. $\mathrm{O}$ autor defende a ideia de que esse clima de impunidade era deliberado, a fim de criar um clima de tensão e medo entre os civis iraquianos e acusa o Departamento de Estado dos Estados Unidos, o principal cliente da Blackwater à época, de incentivar e apoiar esse comportamento agressivo e ameaçador. Scahill publica um trecho da apelação elaborada pelos advogados da Blackwater na qual a empresa defende um tratamento diferenciado pelo governo federal:

é essencial que sua isenção [dos prestadores de serviço] de responsabilidade por baixas seja protegida pelo governo federal e aplicada uniformemente nos tribunais federais. Nada poderia ser mais destrutivo (...) do que expor seus componentes privados aos sistemas de responsabilização penal de cinquenta estados. (SCAHILL, 2008, p. 67)

Em outubro de 2007, o famoso jornal New York Times publicou uma matéria sobre o projeto de lei apresentado pelo Primeiro Ministro do Iraque Nuri Kamal Al-Maliki, que pretendia por fim à impossibilidade de processo aos funcionários privados de segurança dos Estados Unidos. O projeto de lei incluía exigências feitas aos contratados que tornariam mais efetivo o controle do Iraque sobre as empresas contratadas. Dentre as medidas, a reportagem destaca que todas as armas deveriam ser licenciadas pelo Ministério do Interior iraquiano, equipamentos, incluindo helicópteros e veículos blindados, teriam que ser registrado e todos os funcionários estrangeiros teriam que obter o visto do Ministério das Relações Exteriores do

\footnotetext{
${ }^{15}$ SCAHILL, J. Blackwater. São Paulo: Companhia das Letras, 2008, p.13.
} 
Iraque. Como explica o influente político xiita Jalaluddin Al-Sagheer em entrevista à jornalista Alissa Rubin (New York Times),

a Ordem 17 deu-lhes total imunidade e não podemos mais lidar com as empresas de segurança nessas condições (...). A versão do gabinete é apenas o primeiro passo na discussão de como a lei deveria ser escrita, e a segurança e a comissão de defesa do Parlamento vai decidir o que deve ser adicionado e o que deve ser removido (New York Times, 2007) ${ }^{16}$.

Ao defender-se das acusações à Blackwater, após o incidente da Praça Nisour, o fundador da empresa Erik Prince argumenta que suas ações, quanto aos criminosos em sua companhia, estão limitadas à demissão e a sua retirada do país. A lógica de Prince atende à premissa básica de responsabilidade individual do empregado quanto a violações penais, abstendo-se, a empresa, de qualquer obrigação quanto ao processo criminal do empregado, cabendo-lhe a simples rescisão contratual empregatícia, isto é, caso um funcionário da Blackwater cometa um homicídio durante as operações da empresa em território estrangeiro, caberá à companhia a simples demissão do funcionário e não a responsabilização penal. Scahill revela que, ao todo, a empresa de Prince demitiu mais de 120 dos seus agentes operando no Iraque (SCAHILL, 2008, p.32).

A intensificação do uso de companhias militares privadas e a cobertura jornalística de crimes praticados por funcionários contratados destas empresas têm gerado um amplo debate jurídico nos últimos anos, em especial a necessidade de regulação internacional dos limites de atuação destas companhias e procedimentos efetivos de responsabilização penal ${ }^{17}$. A regulação das companhias militares privadas é um tema caro ao Direito Internacional contemporâneo e provoca sérios questionamentos sobre como evitar injustiças para populações já devastadas por intervenções militares (como o Afeganistão e Iraque) e como evitar que tais empresas, que assinam contratos milionários e possuem advogados de elite, se esquivem da responsabilidade penal pelos atos de seus funcionários, bem como se esquivem da aplicação das leis dos países em que atuam, como geralmente tem ocorrido.

\footnotetext{
16 Tradução livre - The New York Times, 30.10.2007. Disponível em: $<$ http://www.nytimes.com/2007/10/31/world/middleeast/31iraq.html?_r=2\&scp=4\&sq=order\%2017\&st=cse >. ${ }^{17}$ Cf., por exemplo, CHESTERMAN, S. LEHNARDT, C. (ed.), From Mercenaries to Market: the rise and regulation of private military companies. Oxford: Oxford University Press, 2007; COCKAYNE, J. Regulating Private Military and Security Companies: the content, negotiation, weaknesess and promisse of the Montreaux Document, Journal of Conflict \& Security Law, v. 13, n. 3, 2008, p. 401-428; KIDANE, W. The Status of Private Military Contractors Under International Humanitarian Law, Denver Journal of International Law and Policy, v. 38, 2010, p. 361-402.
} 


\section{Companhias Militares Privadas na História do Tempo Presente}

Como ressalta Carlos Ortiz, no limiar dos ataques terroristas de 11 de setembro de 2001 ("9/11", tal como ficou conhecido nos Estados Unidos), o interesse sobre o tema do terrorismo e conflitos globais aumentou significativamente. As incursões subsequentes no Afeganistão e Iraque pelos Estados Unidos e seus aliados fomentaram uma maior preocupação com o papel que as forças armadas privadas possuem no conflito contemporâneo. A intensa cobertura da mídia jornalística, junto com a explosão de comunicações de segunda geração e relacionamento social via Internet (divulgação de notícias em tempo real), resultou na maior exposição e debate sobre o exercício privado da violência letal. Somado aos terroristas, rebeldes, insurgentes e crimes organizados, vários tipos de empresas de segurança e companhias militares privadas preenchem a nebulosa narrativa sobre instabilidade global no século XXI (ORTIZ, 2010).

Diante da análise de Ortiz, outras provocações podem ser feitas sobre o tema. Sendo estas empresas privadas, incentivadas pelo produto "guerra”, não poderiam elas fomentar conflitos e tornar a sua presença na defesa necessária, ou mais que isso, essencial? No que concerne ao "risco letal da terceirização da força”, é evidente o círculo vicioso: o fim último das intervenções militares é a eliminação do conflito e consequente paz, entretanto, a companhia privada de segurança - padrão dominante nas intervenções do século XXI depende da guerra ou das “ocupações” para continuar suas atividades. Ou seja, foge do poder estatal o controle total de solução de conflito, possibilitando que as companhias militares privadas fomentem o conflito e a guerra, de modo a garantir uma demanda constante de seus serviços.

Jeremy Scahill, jornalista dedicado à compreensão das atividades da Blackwater (maior companhia militar privada durante o governo George Bush), traz bem essa discussão em seu trabalho investigativo já mencionado. E vai além: o lucro dessas companhias privadas está necessariamente ligado ao aumento da violência. As empresas de guerra altamente remuneradas pelo Estado tornam-se um grupo de interesse forte e armado. Levando a discussão ao extremo, Scahill preocupa-se: "no fim das contas, a quem eles devem sua lealdade?” (SCAHILL, 2008, p. 55).

Ao historiador, cabe um olhar mais atento sobre os elementos econômicos e políticos que estruturam novos fenômenos do século XXI, como a intensificação do uso de companhias militares privadas por grandes potências bélicas como os Estados Unidos da América. As guerras deste século são distintas das do “breve século XX”. A história da guerra depara-se 
com uma nova fase, constituída de diferentes elementos, marcada pelo influxo desestatizante que caracteriza o projeto neoliberal, adotado por governos de países capitalistas avançados nas últimas décadas. A busca pela eficiência, tão presente no discurso das privatizações de serviços públicos, não deixa de estar relacionada com a ascensão das companhias militares privadas. A proposta deste artigo foi a de sinalizar a importância desta discussão para compreender as transformações bélicas que começam a ganhar contornos neste começo de século.

Tal olhar alinha-se com a perspectiva da "história do tempo presente", na qual o historiador se beneficia da compreensão do passado para a análise de novos fenômenos sociais. O desafio é enorme. Como dizia o filósofo alemão Georg W. F. Hegel, a coruja de minerva - símbolo do conhecimento - somente lança seu voo no início do crepúsculo. A compreensão vem com o tempo, olhando para trás. Entender a importância das companhias militares privadas em um contexto de liberalização das guerras e rompimento do monopólio estatal sobre a violência legítima é uma tarefa intelectual marcada por diversos obstáculos. É inegável, todavia, que tal fenômeno tem formatado o novo padrão bélico do complexo século XXI.

\section{Conclusão}

As guerras do século XXI serão profundamente distintas das do passado. Não se trata de profecia, mas de uma consequência da "revolução dos assuntos militares”. Além das novas tecnologias disponíveis para ações militares (muitas delas desconhecidas pela sociedade civil), os governos trabalham com novas formas de operacionalização estratégica dos conflitos. As companhias militares privadas são atores invisíveis. Os canais de comunicação, quando tratam de "tropas militares" ou intervenções bélicas, raramente mencionam as companhias militares que estão a serviço dos Estados Unidos da América em países ocupados por questões políticas. Entretanto, as intervenções militares, desde o fim da Guerra Fria, têm sido caracterizadas pela crescente utilização de companhias privadas que possuem como objeto a prestação de serviços militares que vão desde o planejamento operacional ao fornecimento de equipamentos e pessoal treinado para ações militares.

O presente artigo lançou um breve olhar às companhias militares privadas, distinguindo-as dos tradicionais “mercenários”, existentes há séculos na história da humanidade. O recorte temporal proposto foi bastante preciso: compreender a importância de tais companhias nas intervenções militares colocadas em prática na “Guerra ao Terror”, em 
especial, no Afeganistão e Iraque - locais que se tornaram conhecidos no Ocidente em razão das ocupações dos Estados Unidos da América.

Como alertado anteriormente, o objetivo não foi o de realizar uma análise exaustiva sobre as atividades das companhias militares privadas nas intervenções da “Guerra Fria”. Trata-se do anúncio de uma agenda de pesquisa já iniciada e que trará resultados mais robustos nos próximos anos. O tema é complexo e sugere inúmeras reflexões, algumas aqui apresentadas, como os interesses corporativos por trás do projeto neoliberal de rompimento do monopólio estatal para questões militares e a ausência de um marco regulatório internacional sobre o assunto. Tais reflexões serão tratadas com mais profundidade futuramente.

\title{
WAR ON TERROR AND THE PRIVATIZATION OF FORCE: a first analysis of the use of private companies in the U.S. military interventions after September Eleven (2001-2011)
}

\begin{abstract}
The present article presents a brief historical analysis about the private military companies and its progressive presence in military interventions promoted by the United States of America since the end of Cold War. Departing from a specific point, the period of "War on Terror" promoted by Bush government, the present study proposes a preliminary analysis about the main military companies in the field today, the regulatory limits of private military companies, the interests behind the growing use of this type of private service and the challenges for the comprehension of this phenomenon in the framing of the military issues in the $21^{\text {st }}$ century.
\end{abstract}

Keywords: Private military companies. War on Terror. Foreign policy. United States of America.

\section{Referências}

DALDER, I; LINDSAY, J. American Unbound: the Bush revolution in foreign policy. Washington: Brooking Institution Press, 2003.

HOBSBAWM, E. A Era dos Extremos: o breve século XX (1914-1991). $2^{\mathrm{a}}$ ed. $43^{\mathrm{a}}$ reimpressão. São Paulo: Companhia das Letras, 2010.

HOBSBAWM, E. Globalização, Democracia e Terrorismo. São Paulo: Companhia das Letras, 2007.

HUNTINGTON, S. O Choque de Civilizações e a Recomposição da Ordem Mundial. Rio de Janeiro: Objetiva, 1997. 
JÄGER, T; KÜMMEL, G. Private Military and Security Companies: chances, problems, pitfalls and prospects. Wiesbaden: VS Verlag, 2007.

JOHNSON, C. Blowback: os custos e as consequências do império americano. Rio de Janeiro: Record, 2007.

LANNING, M. L. Mercenaries: soldiers of fortune from ancient Greece to today's private military companies. New York: Ballantine, 2005.

MUNHOZ, S. J. Guerra Fria: um debate interpretativo. In: TEIXEIRA DA SILVA, F. C. (org). O século sombrio. Rio de Janeiro Elsevier/Campus, 2004, p. 261-281.

NOONAN, M. The Future of American Military Strategy a Conference Report. E. Notes. Foreign Research Institute. February, 3, 2006. Disponível em:

<www.fpri.org/enotes/20060203.military.noonan.futureamericanmilitarystrategy.html>.

ORTIZ, C. Private Armed Forces and Global Security: a guide to the issues. Santa Barbara: Greewood Publishing, 2010.

SCAHILL, J. Blackwater: A ascensão do exército mercenário mais poderoso do mundo. São Paulo: Companhia das Letras, 2008.

SCALERCIO, M. A Ação das Corporações Militares Privadas: em que pé está o debate? In: Anais do VI Encontro Nacional de Estudos Estratégicos. Rio de Janeiro, Serviço de Documentação da Marinha, 2007, p. 97-104.

SINGER, P. Corporate Warriors: the rise of privatized military industry. New York: Cornell University Press, 2008.

SINGER, P. Corporate Warriors: the rise of the privatized military industry and its ramification for international security, International Security, v. 26, n. 3, winter, 2001, p. 186220.

TEIXEIRA DA SILVA, F. C. (org.). Enciclopédia de Guerras e Revoluções do século XX. Rio de Janeiro: Elsevier/Campus, 2004.

WEBER, M. Economia e Sociedade: fundamentos da sociologia compreensiva, v. 2. Brasília: Editora UnB, 2004. 